The composition of legumes and sugar beet contains a large number of useful mineral and vitamin substances. The use of composite flour from leguminous crops for the preparation of bakery products helps increase food and biochemical properties. The main objects of this research are chickpea flour, bean flour, dry sugar beet powder, and wheat flour of the first grade. The main problem is an insufficient amount of minerals and vitamins, so the purpose of this work is to enrich bakery products and replace sugar in the recipe with sugar beet powder. The results showed that composite flour and sugar beet increased calcium content by $13.54 \mathrm{mg} / 100 \mathrm{~g}$, iron - by $0.57 \mathrm{mg} / 100 \mathrm{~g}$, potassium - by $141.03 \mathrm{mg} / 100 \mathrm{~g}$, phosphorus - by $38.89 \mathrm{mg} / 100 \mathrm{~g}$, vitamin Aby $0.002 \mathrm{mg} / 100 \mathrm{~g}$, vitamin $B 2-b y$ $0.016 \mathrm{mg} / 100 \mathrm{~g}$, vitamin E-by $0.32 \mathrm{mg} / 100 \mathrm{~g}$, and vitamin PP - by $0.405 \mathrm{mg} / 100 \mathrm{~g}$. Microbiological indicators meet the established norms and requirements; the amount of mesophilic aerobic and facultative-anaerobic microorganisms, yeast, and mold in the test bun was the least compared to the control sample. As a result, it was proved that the use of composite flour of leguminous crops contributes to an increase in the nutritional and biological values of bakery products, and the application of dried sugar beet powder makes it possible to completely exclude sugar from the formulation of the resulting product. Employing this technology and formulations for obtaining bakery products makes it possible to expand the range of bakery products, reduce the duration of the manufacturing process, improve the quality of finished products, increase labor productivity. That also contributes to the improvement of the socio-economic indicators of bakery and confectionery enterprises

Keywords: composite flour, bakery products, legumes, technology, baking, sugar beet
UDC 664.6

DOI: $10.15587 / 1729-4061.2021 .240348$

\section{DEVISING THE FORMULATION AND TECHNOLOGY FOR BAKING BUNS FROM FLOUR OF COMPOSITE MIXTURES AND SUGAR BEET}

\author{
Madina Yakiyayeva \\ Corresponding author \\ $\mathrm{PhD}$, Associate Professor, Deputy Director* \\ Research Institute of Food Technologies \\ E-mail: yamadina88@mail.ru \\ Bay a Muldabekova \\ PhD, Professor* \\ Rauan Mukhtarkhanova \\ $\mathrm{PhD}$, Associate Professor, Head of Department \\ Department of Science Management*** \\ Pernekul Maliktayeva \\ $\mathrm{PhD}$, Professor \\ Department of Standardization and Veterinary Sanitation \\ International Taraz Innovative Institute \\ Zheltoksan str., 69b, Taraz, Republic of Kazakhstan, 080000 \\ A in u r Z heldy b yeva \\ PhD, Associate Professor** \\ Galymzhan Nasrullin \\ $\mathrm{PhD}$ \\ Department of Mechanization and \\ Automation of Production Processes*** \\ Aigerim Toktarova \\ Master Student** \\ *Department of Technology of Bakeries and Processing Productions*** \\ **Department of Food Safety and Quality*** \\ *** Almaty Technological University \\ Tole bi str., 100, Almaty, Republic of Kazakhstan, 050012
}

Received date 02.07.2021 Accepted date 20.09.2021 Published date 29.10.2021
How to Cite: Yakiyayeva, M., Muldabekova, B., Mukhtarkhanova, R., Maliktayeva, P., Zheldybayeva, A., Nasrullin, G., Toktarova, A. (2021). Devising the formulation and technology for baking buns from flour of composite mixtures and sugar beet. Eastern-European Journal of Enterprise Technologies, 5 (11 (113)), 73-84. doi:https://doi.org/10.15587/1729-4061.2021.240348

\section{Introduction}

In recent years, the world's population has shown interest in products for a healthy lifestyle. Leguminous crops and sugar beets have useful properties; sugar beet also improves immunity and hemoglobin, strengthens the entire human body. The bakery industry today is the most dynamically developing one in the world.

One of the promising areas is the use of various plantbased raw materials, which increase the usefulness of the diet by correcting the content of vitamins, minerals, amino acids, proteins, and other substances useful for the body. The use of leguminous crops and sugar beet for the enrichment of bakery products is one of the promising methods of ensuring human nutrient balance. Also, the production of sugar is a complex technological process, so the production and use of sugar beet powder are more efficient for production.

The use of leguminous crops could create a product with improved organoleptic properties, enhanced nutritional and biological value.

Thus, it is a relevant task to form an assortment of bakery products using leguminous crops and sugar beet powder, which would contribute to improving the quality, vitamin and mineral composition. 


\section{Literature review and problem statement}

Paper [1] reports the results of studying sugar products and bakery products prepared from them. It is shown that sugar is a product with a sweet taste. It is added to sweet pastries, chocolate, glazed curds, etc. If one list the products that contain sugar, the list will become endless. Given this, we can conclude that sugar plays an important role in human nutrition. However, it is not profitable for sugar factories to process sugar beet because of the complexity of long-term storage and the technology of separating sugar from sugar beet. Therefore, it is necessary to devise new technologies for the use of sugar without chemical treatment and processing.

Work [2] states that the sugar content in beets (sugariness) ranges from 15 to $21 \%$, and, for beets of average quality, is about $17.5 \%$. The authors of [3] argue that sugar beets are a useful product that once saved peasants from hunger in the years of crop failure; now, it is the main source of sugar in Central Asia. However, sugar production from sugar beet is a complex technology that consists of chemical-physical processes, including diffusion, adhesion, coagulation, solution concentration processes, and sugar crystallization. Therefore, it is necessary to find a way to reduce the complexity of these processes, which would make it possible to bring down production waste and obtain a useful sugar product.

As indicated in work [4], the average chemical composition indicators of sugar beet are as follows: water $-75 \%$, sucrose $-17.5 \%$, fructose and glucose $-2.5 \%$, fiber $-1.2 \%$, pectin substances $-2.4 \%$, nitrogenous substances $-1.1 \%$, proteins and ash $-0.3 \%$. In addition, sugar beets contain a series of amino acids, vitamins, and minerals, therefore, in addition to its direct purpose, it is quite a useful vegetable. The authors of $[5,6]$ state that sugar beet is mostly used as a raw material for the production of granulated sugar and refined sugar. In the process of obtaining sugar, a large volume of by-products is formed at an insignificant yield of the resulting product. In this case, a significant number of secondary products are formed, such as molasses, pulp, defecation precipitate. Under modern conditions, most of the waste from sugar production is practically not disposed of, which leads to their multi-tonnage accumulation, uncontrolled decomposition with the formation of toxic products that pollute the soil, groundwater and surface water, and air. Also, additional investments are required for the processing of sugar beet waste.

As indicated in [7], the disadvantages of the technology used to obtain sugar include low efficiency of sugar beet processing (no more than $60 \%$ of dry matter is used), a limited range of products obtained. During long-term storage, the quality of beets does not remain constant: its sugar content changes, as well as the physicochemical indicators: the mass of root crops decreases due to wilting, there is a decrease in turgor, respiration, and germination, a rotten mass appears as a result of microbiological and enzymatic processes and the formation of foci of mucous bacteriosis. Therefore, it must be quickly processed. But at present, sugar producers do not have time to fully process the raw materials. Spoiled raw materials are not subject to further processing and are not even used as animal feed. In this regard, it would be profitable if one gets dried sugar products, which are used for bakery products, by using simplified technology.
One of the main tasks of the state policy in Kazakhstan in the area of healthy nutrition of the population for the period up to 2020 is to increase the share of produced functional foods that contribute to the effective provision of the human body with the required amount of micro-and macronutrients. Work [8] describes the issue related to providing the population with healthy food. Therefore, in the current situation, it is a relevant and expedient task to devise and implement new technologies and an assortment of products of mass consumption, such as bakery, confectionery, dairy products enriched with essential nutrients that compensate for the shortage of essential components in food. Also, the obtained useful bakery, confectionery, dairy products provide for an increase in immunological resistance of the human body.

According to [9], the biochemical potential of fruits, vegetables, and root crops, especially their concentrates, predetermines a possibility to use them in the food industry in order to increase the nutritional and biological value of food products. Therefore, plant raw materials such as fruits, berries, vegetables, root vegetables, and others, given their low cost, high nutritional and biological value (the content of functional ingredients exceeds $20 \%$ ) could be a strategic agricultural resource. They are also used to make confectionery and other functional food products. Bakery products are food products that contain a sufficient amount of nutrients: carbohydrates, proteins, minerals, etc. In addition, there is a replacement of bakery products in the structure of consumption with other products that consumers consider more useful. Therefore, the structure of production should also change, the share of varieties of bakery products with increased added value, which is considered by the population not just as a source of calories but as a healthy and tasty product, should increase.

Work [10] notes that the expansion of the range of these new competitive products under current conditions is an important national economic task. It can be most effectively solved through the application of modern technologies recommended for use at public catering enterprises or the food industry, making it possible to obtain a high-quality product at low costs for its production. As regards the production of bakery products, this means the use of intensive technologies that make it possible to increase the volume of products, expand the range, improve quality, reduce the cost of products by reducing the long stages of dough preparation. However, manufacturers cannot fully provide the population with useful bakery products. Therefore, manufacturers need to produce, at an industrial scale, high-quality products with natural formulations at affordable prices, relying on existing demand, while creating conditions for both increasing the level of remuneration of employees at the bread industry enterprises and its further development.

Paper [11] provides information on the current use and storage of sugar beet. By using dried sugar beets to make the dough, manufacturers can eliminate the use of sugar in the production of bakery products. In addition, the application of dried sugar beet and flour of composite mixtures from leguminous crops makes it possible to increase the useful properties (vitamin and amino acid composition), quality, organoleptic, rheological, and technological indicators of the finished product. Thus, the development of techniques for making bakery products that increase the efficiency of the 
use of sugar beet and products based on them, which have an enhanced nutritional value, is a relevant task that acquires national economic importance. The study confirmed the relationship between the deterioration of the economic situation in the world and the increase in the production of bread and bakery products, which confirms the social importance of bread and bakery products. The reduction in the volume of bread and bakery products is due to a decrease in the production of short-term storage products, by $1.3-2 \%$ annually. The problems of the industry are related to low economic indicators. It is established that the production of long-term storage products, as well as low humidity, and others, increases annually. Therefore, it is necessary to increase the production of bakery and flour confectionery products of long-term storage with low moisture content to the characteristics of the mass type of production, as well as products with a complex unique formulation (for example, gluten-free bakery and confectionery products), products for "healthy" nutrition, and with herbal additives.

\section{The aim and objectives of the study}

The aim of this work is to devise an innovative highly effective technology for obtaining an assortment of bakery products with the addition of composite mixtures of leguminous crops and sugar beet powder to the basic wheat flour. This will improve the quality and useful properties of bakery products.

To accomplish the aim, the following tasks have been set:

- to devise formulations and preparation regimes of bakery products using sugar beet powder and composite flour of leguminous crops;

- to conduct a comprehensive assessment of the quality of raw materials and devises bakery products (physical and chemical indicators, nutritional value, safety indicators).

\section{The study materials and methods}

The objects of our study are chickpea flour, bean flour, dry sugar beet powder, sugar (for the control sample), wheat flour of the first grade, baker's yeast, egg, milk, and butter.

The main hypothesis of the study assumes that once the organoleptic properties and physical-chemical indicators of the quality of bread are high, then bakery products are of high quality and suitable for human consumption.

The component composition was investigated and substantiated and the technology of bakery products from wheat flour with the use of sugar beet powder and composite flour of leguminous crops was developed in this work.

The use of leguminous crops in the formulation of bakery products should increase the fermentation activity of baking yeast. To increase the nutrients of bakery products, the search for more advanced formulations and cooking technologies is promising. It should be assumed that making bakery products from composite flour and sugar beet powder would make it possible to a greater extent to preserve the biologically valuable substances of the finished product and prevent the formation of undesirable substances that are not digestible compounds for the human body, characteristic of traditional recipes of bakery products.
Technological modes of drying of sugar beet have been devised, and finely ground powder was obtained from it. Fresh sugar beet tubers were thinly sliced and dried at the Hurakan HKN-DHD10 dehydrator (China) at a temperature of $70{ }^{\circ} \mathrm{C}$ for $4.5-5$ hours. After that, they were crushed at the laboratory mill LZM-1M (Russia). The resulting sugar beet powder is shown in Fig. 1.

An assortment of rolls was baked (the formulation was calculated for 1 serving of laboratory batch):

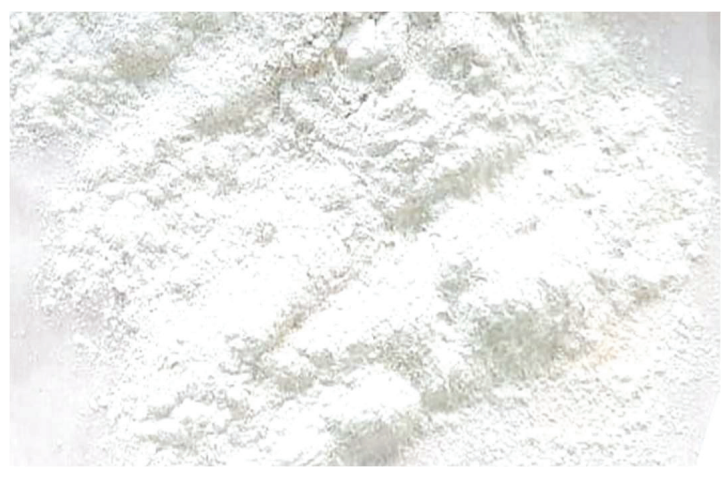

Fig. 1. Dry sugar beet powder

- No. 1 - Bun - a control sample with sugar, based on wheat flour of the first grade (according to the formulation for the bun "Health");

- No. 2 - Bun with the addition of $30 \mathrm{~g}$ sugar beet powder;

- No. 3 - Bun with the addition of $40 \mathrm{~g}$ sugar beet powder;

- No. 4 - Bun made with $15 \%$ bean flour and sugar;

- No. 5 - Bun made with $15 \%$ chickpea flour and sugar;

- No. 6 - Bun made from $15 \%$ bean flour, with the addition of $30 \mathrm{~g}$ sugar beet powder;

- No. 7 - Bun made from $15 \%$ chickpea flour, with the addition of $40 \mathrm{~g}$ sugar beet powder;

- No. 8 - Bun made from $5 \%$ bean and $5 \%$ chickpea flour with the addition of $40 \mathrm{~g}$ sugar beet powder;

- No. 9 - Bun made from $5 \%$ bean and $10 \%$ chickpea flour with the addition of $30 \mathrm{~g}$ sugar beet powder;

- No. 10 - Bun made from $10 \%$ bean and $15 \%$ chickpea flour with the addition of $40 \mathrm{~g}$ sugar beet powder.

The weight of the dough for one sample of a bun is $50 \mathrm{~g}$. One serving of the laboratory batch prepared according to a given formulation yielded, on average, 10-12 units of butter buns.

The following indicators of the raw materials used and the obtained assortment of bakery products were investigated: organoleptic indicators (GOST 5667-85), the mass fraction of moisture (GOST 21094-75), the mass fraction of fat (GOST 5668-68). The mass fraction of protein was determined according to GOST 10846-91. The mass fraction of sugar was determined according to GOST 5672-68, the mass fraction of carbohydrates was determined according to GOST 25832-89. The mass fraction of ash was determined according to GOST 5901-2014. The mass fraction of porosity was determined according to GOST 5669-96. The acidity content was determined according to GOST 5670-96. The iron content was determined according to GOST 26928-86. The content of vitamin A was determined according to GOST R 54635-2011. The content of aflatoxins was determined according to GOST 31748-2012. The number 
of mesophilic aerobic and facultative-anaerobic microorganisms (QMAFAnM) was determined according to GOST 10444.15-94. The number of bacteria of the $E$. coli group (coliform bacteria) (BGKP) was determined according to GOST 31747-2012. The number of osmotolerant yeast and mold fungi was determined according to GOST 28805-90. The crude fiber content was also determined by the Wende method at the Fiwe- 6 analyzer (Austria).

The content of heavy metals and mineral elements was determined by atomic absorption spectroscopy (AAS) at the electrically atomized spectrometer "KVANT-Z. ETA-T” (Russia) with software.

Vitamins B1, B2, PP were determined by capillary electrophoresis at the device Kapel-105M "Lumex" (Russia) (Procedure MVI M 04-41-2005, 2005).

Pesticide contents, including heptachlor, $\alpha-, \beta$ - and $\gamma$-isomers of hexachlorocyclohexane $(\mathrm{HCH})$, dichlorobiphenyl trichloromethyl methane (DDT) and its metabolites, were determined by gas-liquid chromatography.

\section{Devising the technology for a range of bakery products and studying the organoleptic, physical-chemical, and microbiological indicators}

\section{1. Devising the formulations and modes to obtain a} range of bakery products

To prepare a control sample, the formulation for the bun "Health" was used, given in Table 1.

In order to enrich the bakery products, composite flour of leguminous crops was added; dry sugar beet powder was added to exclude sugar from the formulation. Sugar beet powder was added depending on the consistency of the dough, so there were changes in the formulation of the buns. Formulations for the assortment of buns, calculated per $100 \mathrm{~g}$ of flour, are given in Table 2.

The technological scheme of dough preparation and baking mode are shown in Fig. 2.

The baking time depends on the composition and properties of the raw materials used. The time of proofing and baking is given in Table 3 .

Table 1

Formulations for the control sample of a bun

\begin{tabular}{|c|c|c|c|}
\hline \multirow{2}{*}{ No. } & \multirow{2}{*}{ Raw material } & \multicolumn{2}{|c|}{ Raw material quantity } \\
\cline { 3 - 4 } & & Per 1 serving according to the formulation for the bun "Health" & Calculated per 100 g of flour \\
\hline 1 & Flour of the first grade, g & 325 & 100 \\
\hline 2 & Milk, $\mathrm{ml}$ & 150 & 1.85 \\
\hline 3 & Yeast, g & 6 & 15.39 \\
\hline 4 & Egg, g $(1 \mathrm{pc}=50 \mathrm{~g})$ & 50 & 15.39 \\
\hline 5 & Sugar, $\mathrm{g}$ & 50 & 15.39 \\
\hline 6 & Butter, g & 50 & 15.39 \\
\hline
\end{tabular}

Table 2

Formulations for the assortment of buns, calculated per $100 \mathrm{~g}$ of flour

\begin{tabular}{|c|c|c|c|c|c|c|c|c|c|c|c|}
\hline \multirow{2}{*}{ No. } & \multirow{2}{*}{ Raw material } & \multicolumn{10}{|c|}{ Raw material quantity } \\
\hline & & Bun No.2 & Bun No.3 & Bun No. 4 & Bun No.5 & Bun No.6 & Bun No.7 & Bun No.8 & Bun No. 9 & Bun No.10 & Bun No.11 \\
\hline 1 & Flour of the first grade, $g$ & 100 & 100 & 85 & 85 & 85 & 85 & 75 & 85 & 80 & 90 \\
\hline \begin{tabular}{|l|}
2 \\
\end{tabular} & Bean flour, g & 0 & 0 & 15 & 0 & 15 & 15 & 15 & 10 & 15 & 5 \\
\hline 3 & Chickpea flour, g & 0 & 0 & 0 & 15 & 0 & 0 & 10 & 5 & 5 & 5 \\
\hline 4 & Milk, ml & \multicolumn{10}{|c|}{ calculated per $46.15 \mathrm{ml}$} \\
\hline 5 & Yeast, $\mathrm{g}$ & 1.85 & 1.85 & 1.85 & 1.85 & 1.85 & 1.85 & 1.85 & 1.85 & 1.85 & 1.85 \\
\hline 6 & Egg, g & 15.39 & 15.39 & 15.39 & 15.39 & 15.39 & 15.39 & 15.39 & 15.39 & 15.39 & 15.39 \\
\hline \begin{tabular}{|l|}
7 \\
\end{tabular} & Sugar, g & 0 & 0 & 15.39 & 15.39 & 0 & 0 & 15.39 & 0 & 0 & 0 \\
\hline 8 & $\begin{array}{c}\text { Dry powder of sugar } \\
\text { beet, } g\end{array}$ & 9.23 & 12.31 & 0 & 0 & 12.31 & 15.38 & 0 & 9.23 & 12.31 & 12.31 \\
\hline 9 & Butter, g & 15.39 & 15.39 & 15.39 & 15.39 & 15.39 & 15.39 & 15.39 & 15.39 & 15.39 & 15.39 \\
\hline
\end{tabular}

Time of proofing and baking of the control sample and the new range of buns

\begin{tabular}{|c|c|c|c|c|c|}
\hline \multirow{2}{*}{ Sample } & \multicolumn{5}{|c|}{ Time, min } \\
\hline & Sponge dough & Proofing No. 1 & Proofing No. 2 & Baking & Total \\
\hline Bun No. 1 & 15 & 60 & 30 & 10 & 115 \\
\hline Bun No. 2 & 15 & 60 & 40 & 10 & 125 \\
\hline Bun No. 3 & 15 & 70 & 50 & 13 & 148 \\
\hline Bun No. 4 & 15 & 60 & 25 & 8 & 108 \\
\hline Bun No. 5 & 15 & 60 & 30 & 10 & 115 \\
\hline Bun No. 6 & 15 & 70 & 25 & 9 & 104 \\
\hline Bun No. 7 & 15 & 70 & 25 & 12 & 122 \\
\hline Bun No. 8 & 15 & 55 & 25 & 10 & 105 \\
\hline Bun No. 9 & 15 & 75 & 30 & 11 & 131 \\
\hline Bun No. 10 & 15 & 80 & 30 & 9 & 134 \\
\hline
\end{tabular}




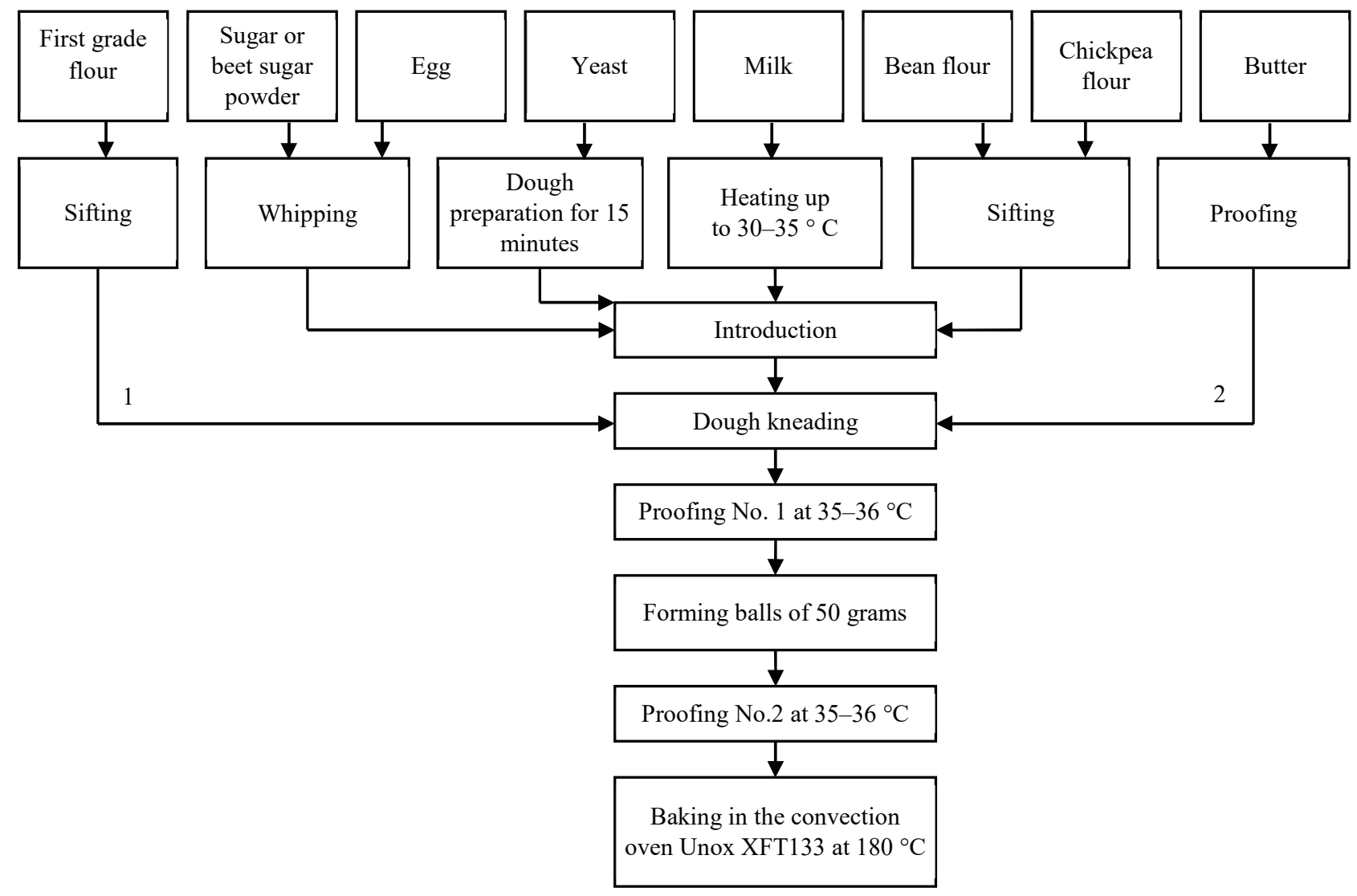

Fig. 2. Technological scheme of dough preparation and baking mode

Data in Table 3 show that in comparison with the control sample, the total baking time of the samples under study, Buns No. 4-6 and No. 8, is less; they are the most optimal.

\section{2. The results of the organoleptic, physical-chemical,} and microbiological studies of the range of buns

For the study, the organoleptic properties of buns of different compositions were determined. The exterior of the resulting control sample and the new range of buns are shown in Fig. $3-12$.

The resulting products in Fig. 3-12 demonstrate the organoleptic indicators, which are given in Table 4.

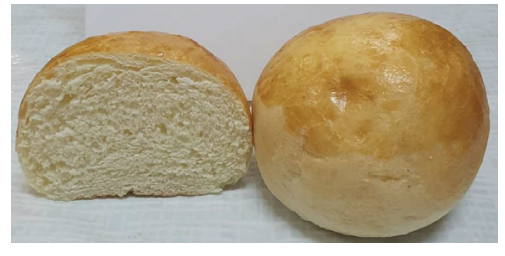

$a$

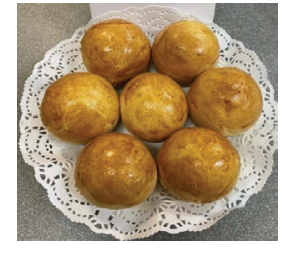

$b$
Fig. 3. Bun No. 1 - control sample with sugar, based on wheat flour of the first grade: $a$-enlarged; $b$ - external appearance

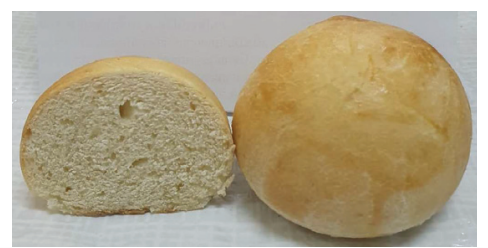

a

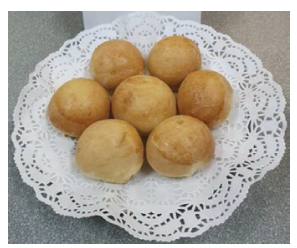

$b$
Fig. 4. Bun No. 2 with the addition of 30 grams of sugar beet powder: $a$-enlarged; $b$-external appearance
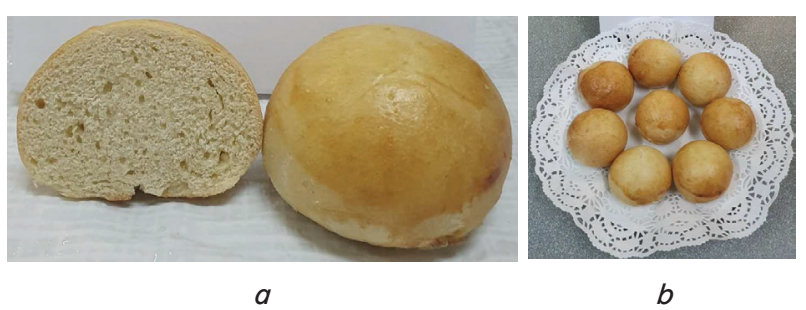

Fig. 5. Bun No. 3 with the addition of 40 grams of sugar beet powder: $a$-enlarged; $b$ - external appearance

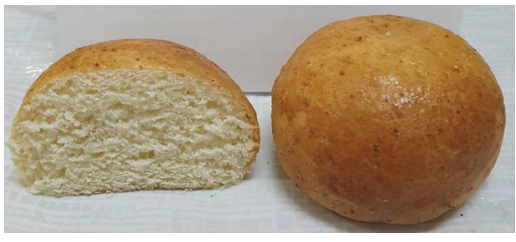

a

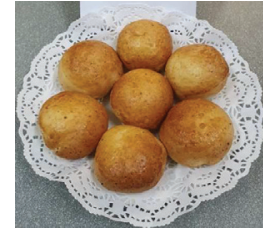

$b$
Fig. 6. Bun No. 4, prepared from $15 \%$ bean flour with sugar: $a$-enlarged; $b$ - external appearance

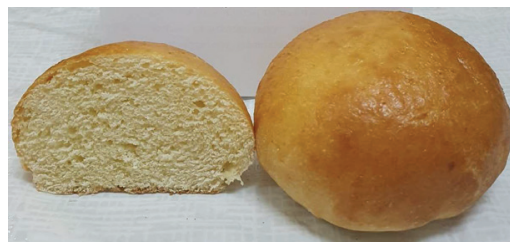

a

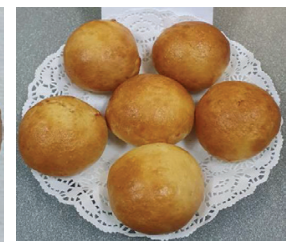

$b$
Fig. 7. Bun No. 5, prepared from $15 \%$ chickpea flour with sugar: $a$-enlarged; $b$-external appearance

Data in Table 4 and Fig. 3-12 show that the organoleptic characteristics of the new range of buns deviate 
from the control sample. It was established that the introduction of composite flour and sugar beet powder had a positive effect on the organoleptic indicators of prototypes: the finished products had a pleasant, moderately pronounced taste and aroma, glossy crust.

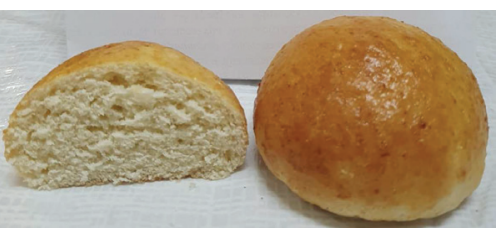

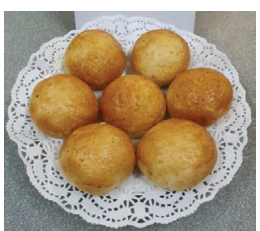

$b$
Fig. 8. Bun No. 6, prepared from $15 \%$ bean flour and with the addition of 30 grams of sugar beet powder: $a$ - enlarged; $b$ - external appearance

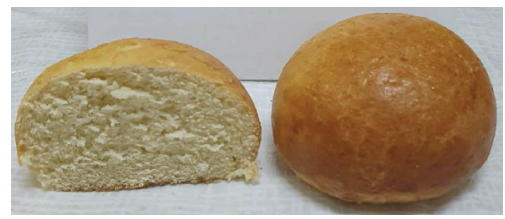

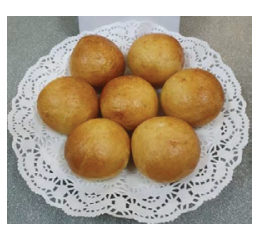

$b$
Fig. 9. Bun No. 7, prepared from $15 \%$ chickpea flour and with the addition of 40 grams of sugar beet powder: $a$-enlarged; $b$ - external appearance

Next, the physical-chemical and safety indicators were investigated. The results of the physical-chemical parameters of the range of buns are shown in Fig. 13.

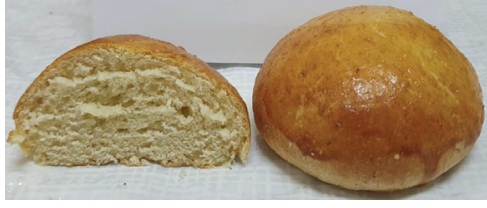

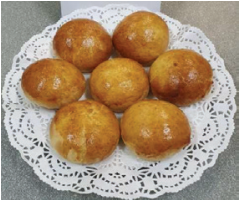

$b$

Fig. 10. Bun No. 8, prepared from $5 \%$ bean and $5 \%$ chickpea flour with the addition of 40 grams of sugar beet powder: $a$-enlarged; $b$ - external appearance

In order to exclude sugar from the bun formulation, it was replaced with dry sugar beet powder; in addition, to enrich them with minerals, vitamins, and nutrients, chickpea and bean flour were added. For comparison, buns prepared with the addition of separately dry powder of sugar beet, chickpea, bean flour of different ratios and quantities were studied to determine their qualities in the resulting product.

The content of calcium and iron in the range of buns is shown in Fig. 14. The content of potassium and phosphorus in the range of buns is shown in Fig. 15. The content of vitamins A, B1, and B2 in the range of buns is shown in Fig. 16. The content of vitamins $\mathrm{E}$ and $\mathrm{PP}$ in the range of buns is shown in Fig. 17.

Data in Fig. 13-17 show that in comparison with the control image, the new range of buns, made from composite flour and sugar beet powder, contains a significant volume of mineral elements and vitamins.

The content of toxic elements, mycotoxins, pesticides, and microbiological indicators were also investigated. The results of the study are given in Table 5 .

Table 4

Organoleptic characteristics of the control sample and the new range of buns

\begin{tabular}{|c|c|c|c|c|c|}
\hline Bun & Color & Aroma & Surface & Taste & Shape \\
\hline Bun No.1 & Light yellow & $\begin{array}{l}\text { Characteristic of this } \\
\text { type of product }\end{array}$ & $\begin{array}{l}\text { Smooth, without } \\
\text { breaks }\end{array}$ & $\begin{array}{l}\text { Characteristic of this } \\
\text { type of product }\end{array}$ & $\begin{array}{l}\text { Rounded, not spreading, } \\
\text { without pressing }\end{array}$ \\
\hline Bun No. 2 & Light brown & $\begin{array}{l}\text { Characteristic of this } \\
\text { type of product with } \\
\text { a pronounced smell of } \\
\text { sugar beet }\end{array}$ & $\begin{array}{l}\text { Smooth, without } \\
\text { breaks }\end{array}$ & $\begin{array}{l}\text { Characteristic of this } \\
\text { type of product with } \\
\text { a pronounced taste of } \\
\text { sugar beet }\end{array}$ & $\begin{array}{l}\text { Rounded, not spreading, } \\
\text { without pressing }\end{array}$ \\
\hline Bun No. 3 & Light brown & $\begin{array}{l}\text { Characteristic of this } \\
\text { type of product with } \\
\text { a pronounced smell of } \\
\text { sugar beet }\end{array}$ & $\begin{array}{l}\text { Smooth, without } \\
\text { breaks }\end{array}$ & $\begin{array}{l}\text { Characteristic of this } \\
\text { type of product with } \\
\text { a pronounced smell of } \\
\text { sugar beet }\end{array}$ & $\begin{array}{l}\text { Rounded, not spreading, } \\
\text { without pressing }\end{array}$ \\
\hline Bun No. 4 & Light yellow & $\begin{array}{l}\text { Characteristic of this } \\
\text { type of product }\end{array}$ & $\begin{array}{l}\text { Smooth, without } \\
\text { breaks }\end{array}$ & $\begin{array}{l}\text { Characteristic of this } \\
\text { type of product }\end{array}$ & $\begin{array}{l}\text { Rounded, slightly } \\
\text { spreading, without } \\
\text { pressing }\end{array}$ \\
\hline Bun No. 5 & Light yellow & $\begin{array}{l}\text { Characteristic of this } \\
\text { type of product }\end{array}$ & $\begin{array}{l}\text { Smooth, without } \\
\text { breaks }\end{array}$ & $\begin{array}{l}\text { Characteristic of this } \\
\text { type of product }\end{array}$ & $\begin{array}{c}\text { Rounded, not spreading, } \\
\text { without pressing }\end{array}$ \\
\hline Bun No.6 & Yellow & $\begin{array}{l}\text { Characteristic of this } \\
\text { type of product }\end{array}$ & $\begin{array}{l}\text { Smooth, without } \\
\text { breaks }\end{array}$ & $\begin{array}{l}\text { Characteristic of this } \\
\text { type of product }\end{array}$ & $\begin{array}{c}\text { Rounded, not spreading, } \\
\text { without pressing }\end{array}$ \\
\hline Bun No. 7 & Light brown & $\begin{array}{l}\text { Characteristic of this } \\
\text { type of product }\end{array}$ & $\begin{array}{l}\text { Smooth, without } \\
\text { breaks }\end{array}$ & $\begin{array}{l}\text { Characteristic of this } \\
\text { type of product }\end{array}$ & $\begin{array}{c}\text { Rounded, not spreading, } \\
\text { without pressing }\end{array}$ \\
\hline Bun No. 8 & Light brown & $\begin{array}{l}\text { Characteristic of this } \\
\text { type of product }\end{array}$ & $\begin{array}{l}\text { Smooth, without } \\
\text { breaks }\end{array}$ & $\begin{array}{l}\text { Characteristic of this } \\
\text { type of product }\end{array}$ & $\begin{array}{c}\text { Rounded, not spreading, } \\
\text { without pressing }\end{array}$ \\
\hline Bun No. 9 & Light yellow & $\begin{array}{l}\text { Characteristic of this } \\
\text { type of product }\end{array}$ & $\begin{array}{l}\text { Smooth, without } \\
\text { breaks }\end{array}$ & $\begin{array}{l}\text { Characteristic of this } \\
\text { type of product }\end{array}$ & $\begin{array}{c}\text { Rounded, not spreading, } \\
\text { without pressing }\end{array}$ \\
\hline Bun No.10 & Light yellow & $\begin{array}{l}\text { Characteristic of this } \\
\text { type of product }\end{array}$ & $\begin{array}{l}\text { Smooth, with } \\
\text { breaks }\end{array}$ & $\begin{array}{l}\text { Characteristic of this } \\
\text { type of product }\end{array}$ & $\begin{array}{c}\text { Rounded, not spreading, } \\
\text { without pressing }\end{array}$ \\
\hline
\end{tabular}




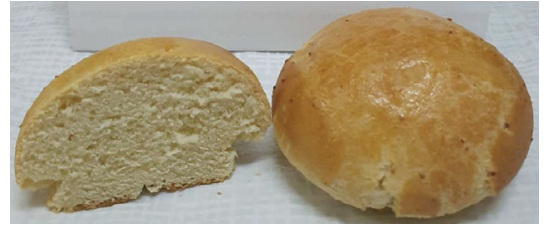

$a$

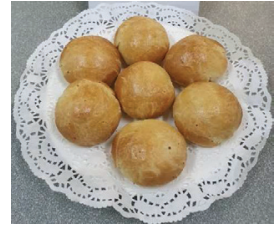

$b$

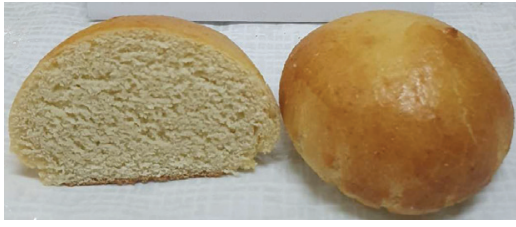

a

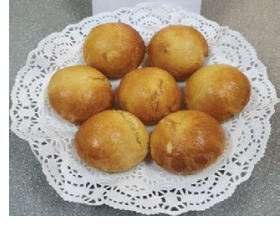

Fig. 11. Bun No. 9, prepared from $5 \%$ bean and $10 \%$ chickpea flour with the addition of 30 grams of sugar beet powder: $a$ - enlarged; $b$ - external appearance

Fig. 12. Bun No. 10, prepared from $10 \%$ bean and $15 \%$ chickpea flour with the addition of 40 grams of sugar beet powder: $a$-enlarged; $b$ - external appearance

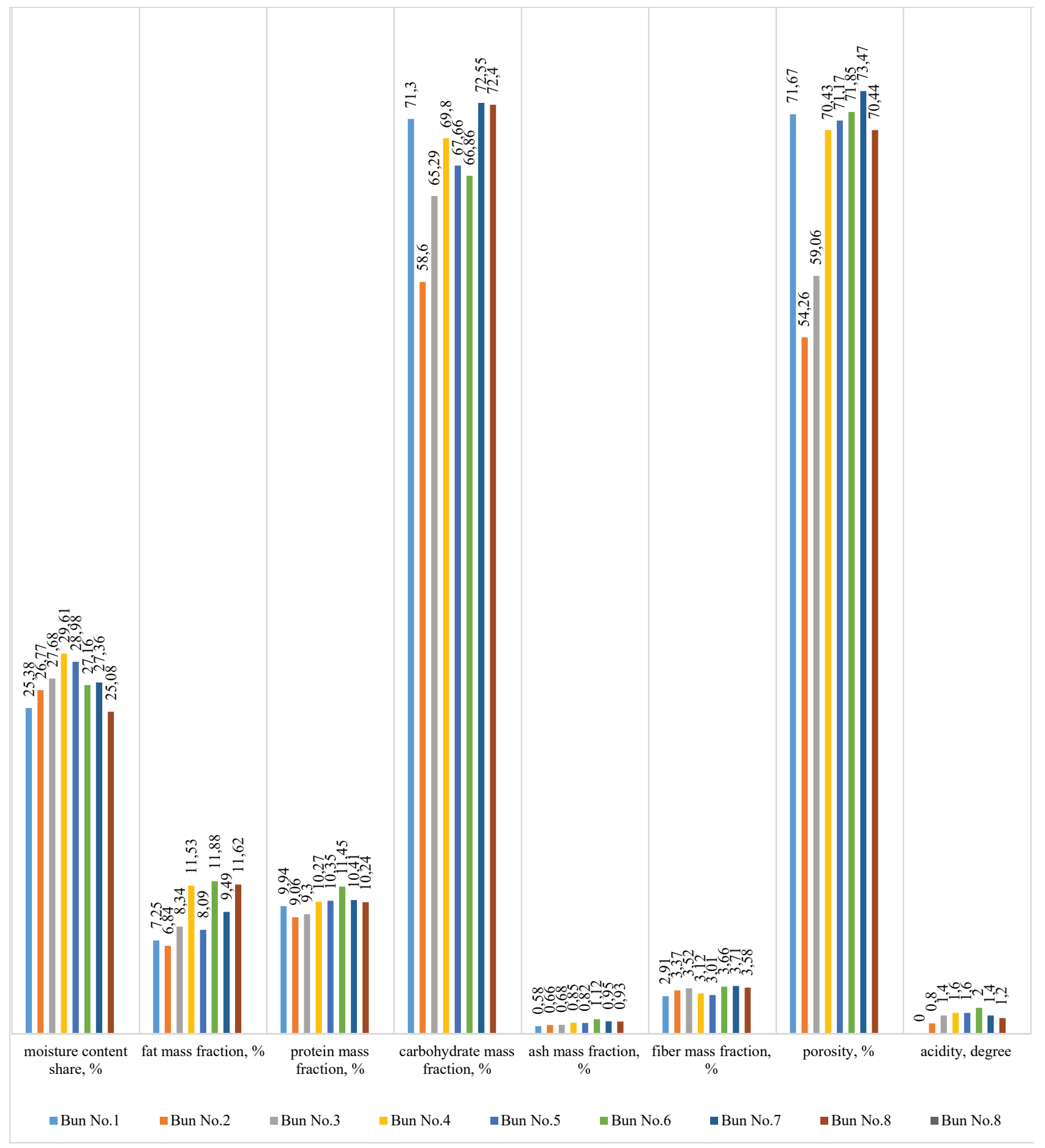

Fig. 13. Physical-chemical parameters of the range of buns 


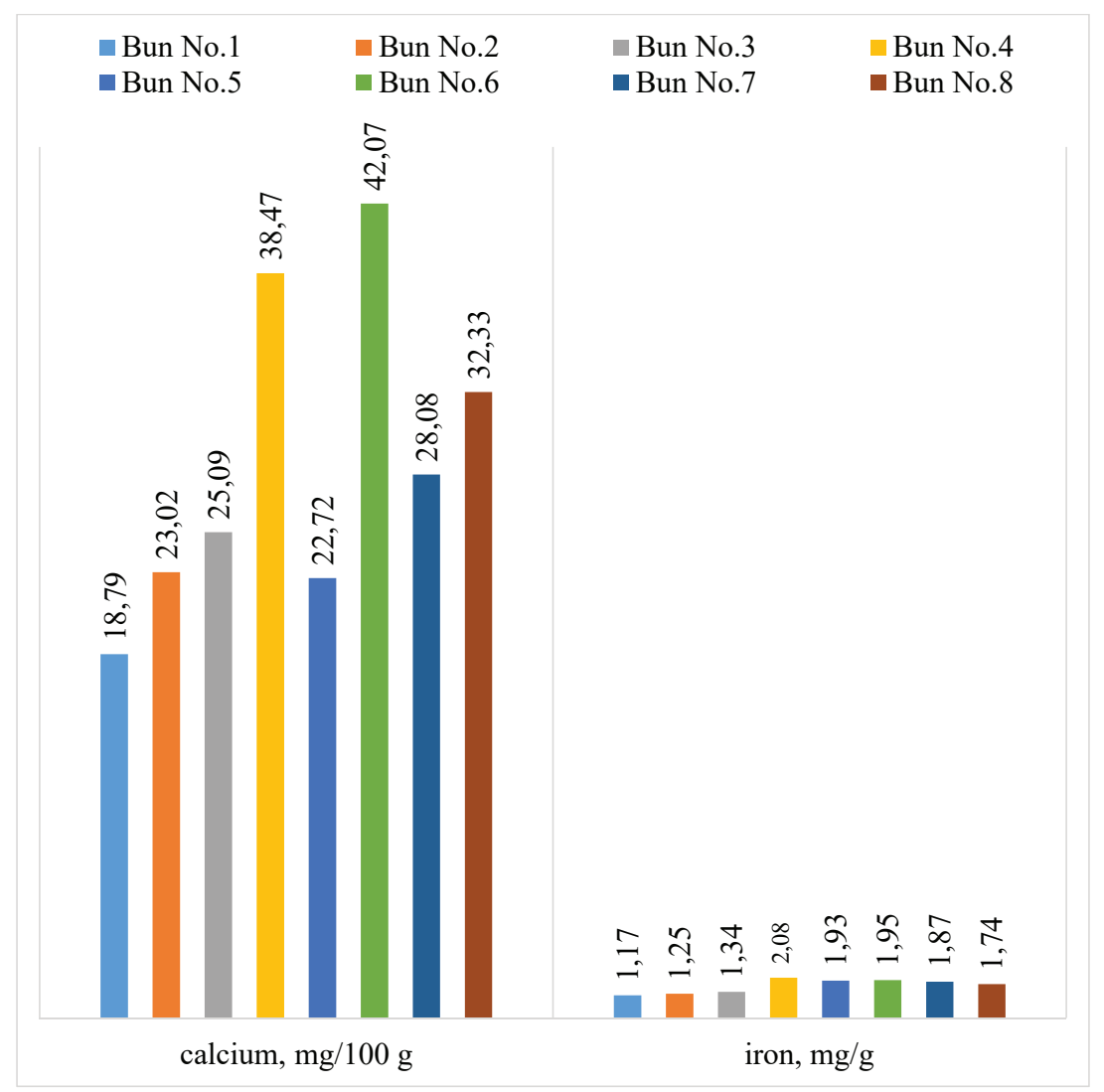

Fig. 14. The content of calcium and iron in the range of buns

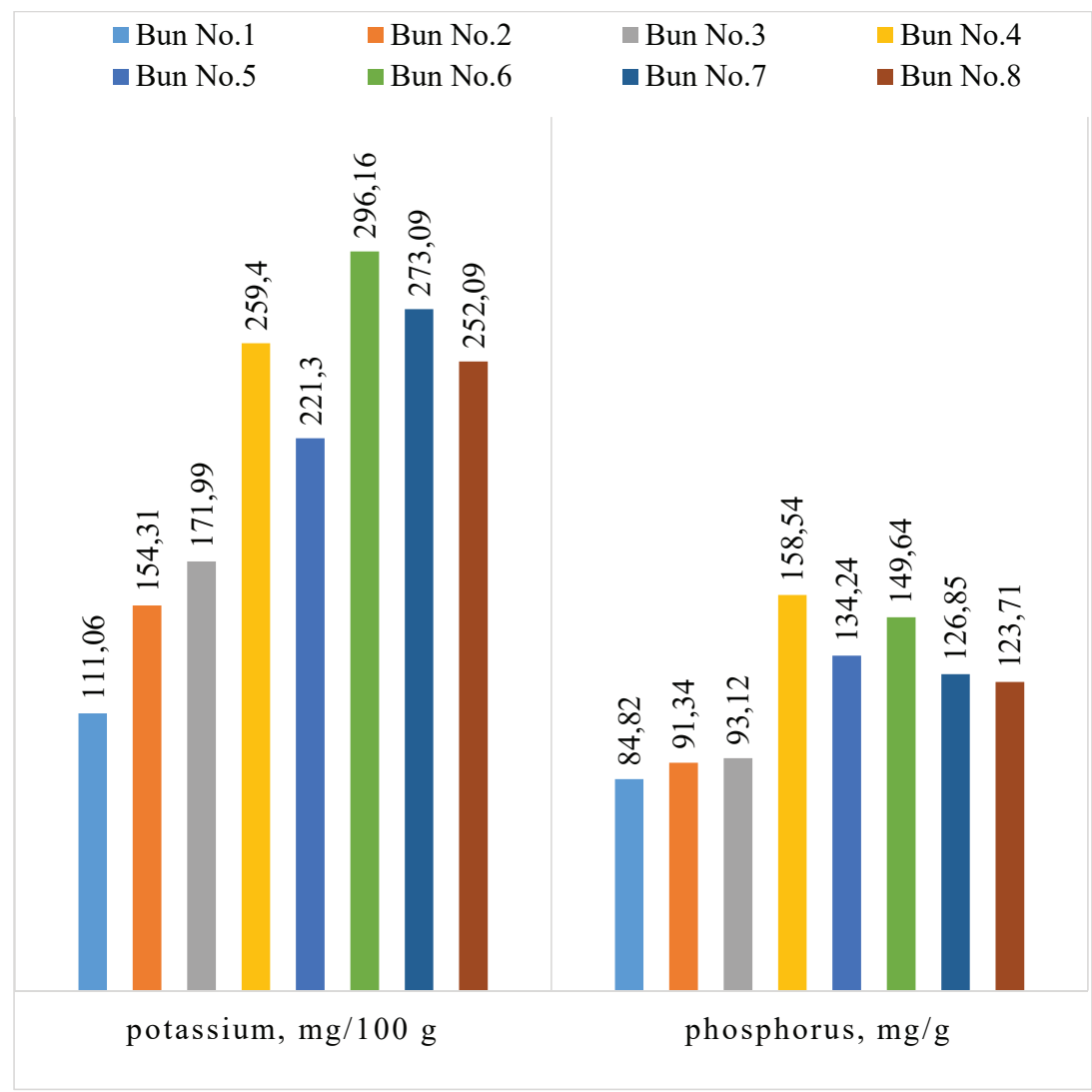

Fig. 15. The content of potassium and phosphorus in the range of buns 


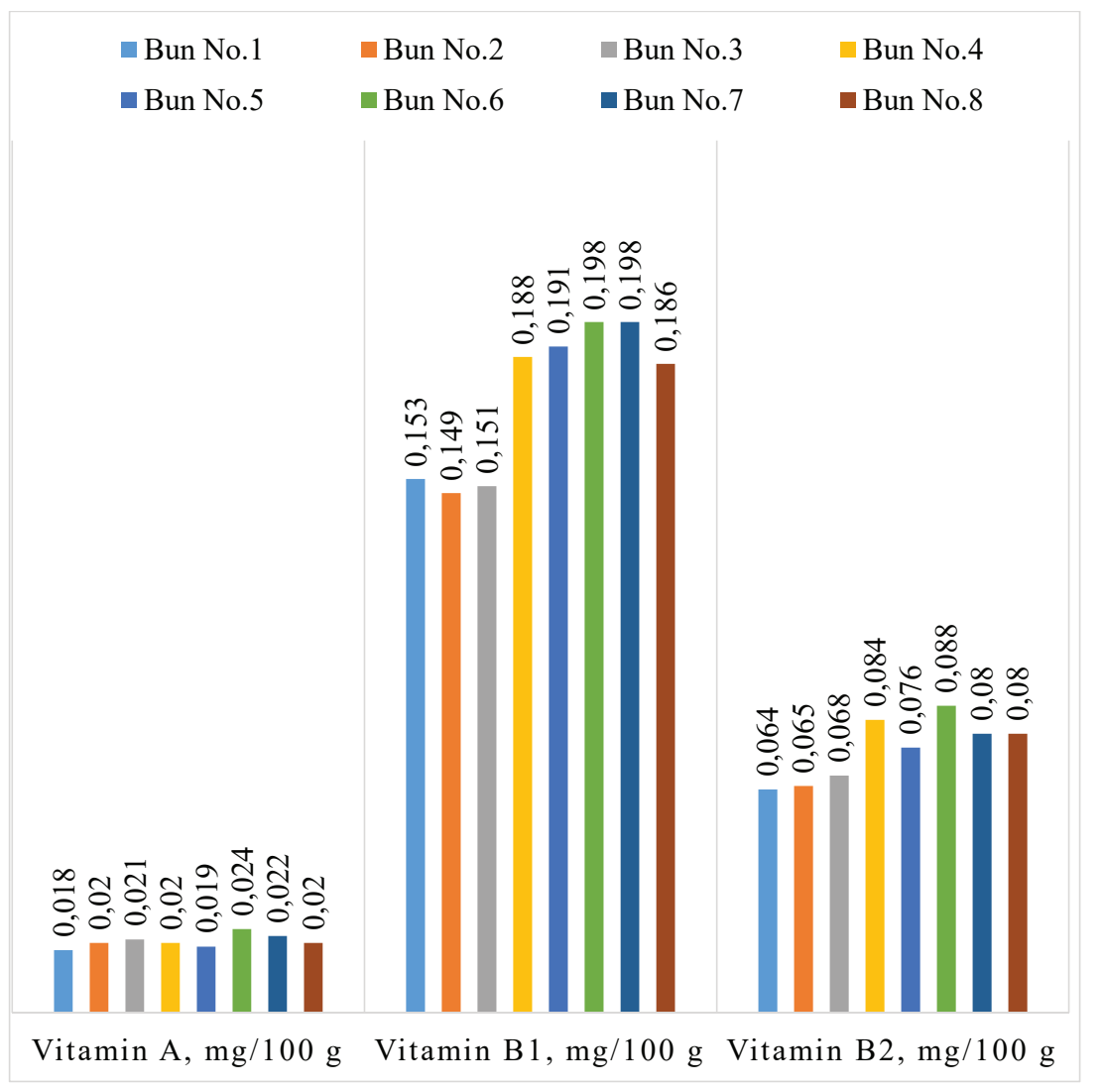

Fig. 16. The content of vitamins $A, B 1$, and $B 2$ in the range of buns

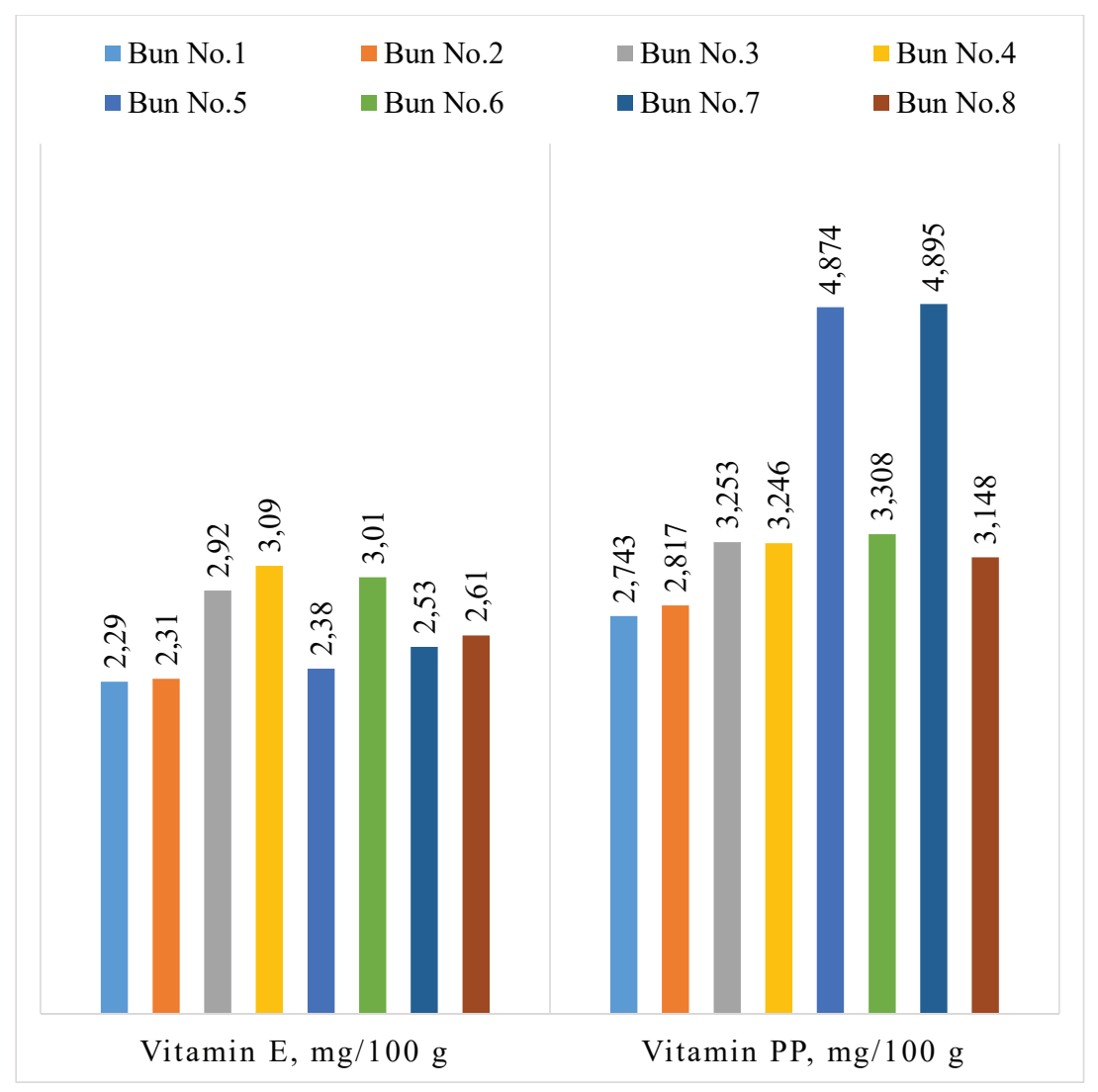

Fig. 17. The content of vitamins $E$ and $P P$ in the range of buns 
Safety indicators of the range of buns

\begin{tabular}{|c|c|c|c|c|c|c|c|c|}
\hline \multirow{2}{*}{$\begin{array}{l}\text { Name of indicators, } \\
\text { units of measurement }\end{array}$} & \multicolumn{8}{|c|}{ Actual results } \\
\hline & Bun No. 1 & Bun No. 2 & Bun No. 3 & Bun No. 4 & Bun No. 5 & Bun No. 6 & Bun No. 7 & Bun No. 8 \\
\hline \multicolumn{9}{|c|}{ Toxic elements: } \\
\hline cadmium, mg $/ \mathrm{kg}$ & Not detected & 0.0008 & 0.0011 & Not detected & Not detected & 0.0004 & Not detected & Not detected \\
\hline lead, mg/kg & Not detected & 0.0012 & 0.0017 & Not detected & Not detected & 0.0009 & 0.0010 & Not detected \\
\hline \multicolumn{9}{|c|}{ Mycotoxins: } \\
\hline $\begin{array}{c}\text { aflatoxin B1, } \\
\text { mg/kg }\end{array}$ & Not detected & Not detected & Not detected & Not detected & Not detected & Not detected & Not detected & Not detected \\
\hline \multicolumn{9}{|c|}{ Pesticides: } \\
\hline Heptachlor, mg/kg & Not detected & Not detected & Not detected & Not detected & Not detected & Not detected & Not detected & Not detected \\
\hline $\begin{array}{c}\mathrm{HCCH}(\alpha, \beta, \\
\gamma \text {-isomers }), \mathrm{mg} / \mathrm{kg}\end{array}$ & Not detected & Not detected & Not detected & Not detected & Not detected & Not detected & Not detected & Not detected \\
\hline $\begin{array}{l}\text { DDT and its metabo- } \\
\text { lites, } \mathrm{mg} / \mathrm{kg}\end{array}$ & Not detected & Not detected & Not detected & Not detected & Not detected & Not detected & Not detected & Not detected \\
\hline \multicolumn{9}{|c|}{ Microbiological indicators: } \\
\hline QMAFAnM, CFU/g & $7 * 10^{3}$ & $12 * 10^{3}$ & $9 * 10^{3}$ & $13 * 10^{3}$ & $11 * 10^{3}$ & $13 * 10^{3}$ & $4 * 10^{3}$ & $5^{*} 10^{3}$ \\
\hline $\begin{array}{c}\text { BGKP (coliforms) } \\
\text { per } 1.0 \text { g of product, } \\
\text { CFU/g }\end{array}$ & Not detected & Not detected & Not detected & Not detected & Not detected & Not detected & Not detected & Not detected \\
\hline Yeast, CFU/g & Not detected & Not detected & Not detected & Not detected & 1 & Not detected & Not detected & Not detected \\
\hline Molds, CFU/g & 7 & 4 & 3 & 4 & Not detected & 4 & 6 & 3 \\
\hline
\end{tabular}

Data in Table 5 show that the resulting range of buns, made from composite flour and sugar beet powder, is safe for the human body.

\section{Discussion of results of studying the range of bakery products}

An innovative highly effective technology for obtaining bakery products with the addition of composite mixtures of leguminous crops and sugar beet powder to the main flour has been devised.

The data in Table 4 and Fig. 3-12 allow us to draw the following conclusion: in comparison with the control sample No. 1, Buns No. 4-8 do not deviate from it and showed better results in terms of their organoleptic indicators. As regards the organoleptic indicators, the following shortcomings were revealed: Buns No. 2, 3 are not elastic, the shape of bun No. 9 is not smooth; the crumb of bun No. 9 is not elastic, the surface of bun No. 10 had breaks. It was found that chickpeas give the bun volume, and beans affect the time of proofing and preparation of the dough. Based on these results of our study, the samples of buns No. 1-8 were selected to determine the physical-chemical and safety indicators. Of these, the indicators of bun No. 8, prepared from composite flour and sugar beet, were compared with the control sample. The condition of the crumb was the same in almost all samples:

1. Baking quality: all samples were properly baked, not wet to the touch; samples No. 2, 3, No. 9 were not elastic, and the rest were elastic.

2. Kneading: in all samples, there were no lumps and traces of improper kneading.

3. Porosity: in all samples, it was developed, without voids, and compacted.

The data in Fig. 13 show that compared with the control sample, the moisture content of buns No. 4-7 is higher by $1.39-54.23 \%$. This proves that chickpea flour absorbs more moisture, so it is necessary to reduce the amount of wheat flour in the formulation. In terms of the mass share of fat compared to the control, sample No. 2 showed the lowest result, its content was equal to $6.84 \%$, and the fat content of the remaining buns was higher by $0.84-4.63 \%$. The protein content of buns No. $4-8$ was higher by $0.3-1.51 \%$. The mass fraction of protein in the control sample was $9.94 \%$, and in bun No. 8 was close to $10.24 \%$. The mass fraction of carbohydrate in samples No. 7 and No. 8 is higher, compared to the control sample, by $1.25 \%$ and $1.1 \%$, respectively. Chickpeas and beans are rich in fiber, minerals, so the ash content was higher in the buns made from them. The ash content in dry sugar beet powder, chickpea and bean flour is very high, so all buns, except for the control sample, have a high ash content. The acidity of the control sample was 1.2 degrees, bun No. 2 - close to 0.8 degrees, and bun No. 8 - close to 1.2 degrees, and the rest are higher by $0.2-0.8$ degrees compared to the control sample.

The data in Fig. 14, 15 show that the content of calcium, iron, potassium, and phosphorus is higher by 1-2 times compared to the control sample. That proves that the bean and chickpea flour contribute to the increase of these mineral elements in buns. The calcium content in bun No. 1 (control sample) was $18.79 \mathrm{mg} / 100 \mathrm{~g}$, and in bun No. 8 , prepared from $5 \%$ bean and $5 \%$ chickpea flour with the addition of 40 grams of sugar beet powder, was $32.33 \mathrm{mg} / 100 \mathrm{~g}$. The iron content in bun No. 1 (control sample) was $1.17 \mathrm{mg} / 100 \mathrm{~g}$, and in bun No. 8 - close to $1.74 \mathrm{mg} / 100 \mathrm{~g}$. The potassium content in bun No. 1 was $111.06 \mathrm{mg} / 100 \mathrm{~g}$, and in bun No. 8 - more than twice, that is, close to $252.09 \mathrm{mg} / 100 \mathrm{~g}$. The phosphorus content in bun No. 1 was $84.82 \mathrm{mg} / 100 \mathrm{~g}$, and in bun No. 8 was equal to $123.71 \mathrm{mg} / 100 \mathrm{~g}$.

The data in Fig. 16, 17 show that the content of vitamin A is not particularly different, that is, in bun No. 1, was $0.018 \mathrm{mg} / 100 \mathrm{~g}$, and in bun No. 8 - close to $0.020 \mathrm{mg} / 100 \mathrm{~g}$. Chickpea and bean flour is rich in vitamins B1, B2, E, and $\mathrm{PP}$, so when one adds them to the formulation of buns, 
the content of these vitamins increases accordingly. The amount of vitamin B1 in bun No. 1 was $0.153 \mathrm{mg} / 100 \mathrm{~g}$. and in bun No. 8 - close to $0.186 \mathrm{mg} / 100 \mathrm{~g}$, the content of vitamin B2 in bun No. 1 was $0.064 \mathrm{mg} / 100 \mathrm{~g}$, and in bun No. 8 - close to $0.080 \mathrm{mg} / 100 \mathrm{~g}$. The content of vita$\min \mathrm{E}$ in bun No. 1 was $2.29 \mathrm{mg} / 100 \mathrm{~g}$, and in bun No. 8 $2.61 \mathrm{mg} / 100 \mathrm{~g}$. The content of vitamin PP in bun No. 1 was $2.743 \mathrm{mg} / 100 \mathrm{~g}$, and in bun No. $8-3.148 \mathrm{mg} / 100 \mathrm{~g}$.

The data in Table 5 show that toxic elements are found in buns No. 2, 3, 6, and No. 7 (lead only), although within the permissible concentration. No mycotoxins or pesticides were found in all the bun samples. The microbiological indicators show that the number of mesophilic aerobic and facultatively anaerobic microorganisms (QMAFAnM, or total microbial number-OMF) in the samples of bun No. 7 and No. 8 is less, compared to the control sample of the bun. Bacteria of the E. coli group (BGKP) were not found in all the samples of the bun studied. Yeast was found in bun No. 5, prepared from $15 \%$ chickpea flour with sugar, the content was $1 \mathrm{CFU} / \mathrm{g}$ but did not exceed the established norms. The amount of mold in control sample No. 1 was 7 CFU/g, in other samples of the bun, less, and it was not detected in bun No. 5 .

To summarize, we can conclude on the best formulation in the technology - this is the formulation of bun No. 8, prepared from $5 \%$ bean and $5 \%$ chickpea flour with the addition of $40 \mathrm{~g}$ sugar beet powder (per 1 serving of laboratory batch). In this formulation, dry sugar beet powder completely replaces sugar and this bun is enriched with useful properties, vitamins, and mineral elements. Therefore, this option is offered for the production of high-quality and useful buns.

The use of bean and chickpea flour for the preparation of buns reduces the time of baking and fermentation, promotes the fermentation process while dry sugar beet powder reduces the spread of dough blanks.

As a result of our study, a formulation and technology for obtaining bakery products from flour of composite mixtures without the use of sugar were devised, contributing to improving the quality, useful properties, and safety of the finished product.

The devised new technology of composite flour with the addition of chickpea and bean flour with a high content of protein, vitamins, and other useful properties makes it possible to activate biotechnological production processes and save wheat flour.

The comparative results of our study showed that a reasonable best version of the technology (technology of cooking bun No. 8) makes it possible to reduce the baking time compared to the control sample. In particular, it was found that the baking time was reduced by 7 minutes, and was equal to 105 minutes. At the same time, an increase in nutritional value and safety indicators was established, in comparison with the control sample and other ranges of bakery products.

The expected social effect would mean that the use of flour composite mixtures from leguminous crops and sugar beets, which have many useful properties (vitamin, immune-modulation, etc.), in the production of bakery and flour confectionery products contributes to the creation of environmentally friendly, useful, and highly effective products that are very relevant for the whole world.

The popularity of healthy food, it would seem, should negatively affect the sale of bakery products but manufacturers need to attract the attention of consumers with new varieties of bakery products - these are useful products with fiber, rich in vitamins, low-calorie content, etc.

Our study makes it possible to address the following issues of manufacturers of bakery products:

- to increase the volume of production of bakery and flour confectionery products of long-term storage;

- to increase the profitability of production;

- to increase the competitiveness of products in the domestic and foreign markets;

- to provide low-calorie products, increase nutritional value, the content of micro-and macronutrients, vitamins, and other useful substances;

- to make it possible to get products for "healthy" nutrition, as well as with plant-based supplements.

The advantages of using this study include the following:

- reduction of cooking time;

- exclusion of processed sugar from the formulation and the use of natural sugar beet powder;

- enrichment of bakery products with leguminous crops and, at the same time, an increase in vitamins, macro-and microelements, nutritional and biological value in the product;

- ensuring the quality and safety of bakery products.

\section{Conclusions}

1. It has been established that adding composite flour and sugar beet powder exerts a noticeable effect on the quality indicators of bakery products. At the same time, it is possible not only to diversify the range of bakery products and improve its quality but also to increase the nutritional and biological value of the product. A range of bakery products with the addition of composite mixtures of leguminous crops and sugar beet powder to the main wheat flour was obtained in order to improve the quality and useful properties. The results showed that the control sample was prepared within 115 minutes, bun No. 4 over 108 minutes, bun No. 5 115 minutes, bun No. 6 - 104 minutes, bun No. 8 -105 minutes. Accordingly, the baking time of buns No. 4-6 and No. 8 are the best.

2. The best technology for baking a bun from composite mixtures of leguminous crops and dry sugar beet powder is that for bun No. 8. It was prepared according to the following formulation (per $100 \mathrm{~g}$ ): wheat flour of the first grade $-73.23 \mathrm{~g}$, chickpea flour $-5 \mathrm{~g}$, bean flour $-5 \mathrm{~g}$, milk - as calculated (to the required consistency of the dough). In addition, we added dry yeast $-1.85 \mathrm{~g}$, egg $-15.39 \mathrm{~g}$, dry sugar beet powder $-12.31 \mathrm{~g}$, butter $-15.39 \mathrm{~g}$. The kneading and proofing time is 95 minutes, baking time is 10 minutes. This product would be in demand by people as it has preventive properties, original shape, and special taste. The manufacturing of these products can be organized at small-scale enterprises, in small bakeries.

\section{Acknowledgments}

This study was funded within project No. AP08955357 "Development of a highly effective technology for obtaining bakery and flour confectionery products from flour of composite mixtures without the use of sugar" of the Ministry of Education and Science of the Republic of Kazakhstan. We express our gratitude to the management of JSC "Almaty Technological University" for the assistance and help in the implementation of the pilot study. 


\section{References}

1. Agengo, F. B., Onyango, A. N., Serrem, C. A., Okoth, J. (2020). Efficacy of compositing with snail meat powder on protein nutritional quality of sorghum-wheat buns using a rat bioassay. Journal of the Science of Food and Agriculture, 100 (7), 2963-2970. doi: https://doi.org/10.1002/jsfa.10324

2. Catapang, R. G. (2019). Acceptability of veggie-steamed bun. International Journal of Scientific \& Technology Research, 8 (8), $1643-1647$.

3. Cevoli, C., Nallan Chakravartula, S. S., Rosa, M. D., Fabbri, A. (2019). Drying of coating on bun bread: Heat and mass transfer numerical model. Biosystems Engineering, 181, 1-10. doi: https://doi.org/10.1016/j.biosystemseng.2019.02.009

4. Zhu, F., Li, J. (2019). Physicochemical properties of steamed bread fortified with ground linseed (Linum usitatissimum). International Journal of Food Science \& Technology, 54 (5), 1670-1676. doi: https://doi.org/10.1111/ijfs.14043

5. Paznocht, L., Kotíková, Z., Orsák, M., Lachman, J., Martinek, P. (2019). Carotenoid changes of colored-grain wheat flours during bun-making. Food Chemistry, 277, 725-734. doi: https://doi.org/10.1016/j.foodchem.2018.11.019

6. Bostic, J. N., Palafox, S. J., Rottmueller, M. E., Jahren, A. H. (2015). Effect of baking and fermentation on the stable carbon and nitrogen isotope ratios of grain-based food. Rapid Communications in Mass Spectrometry, 29 (10), 937-947. doi: https://doi.org/10.1002/ rcm.7178

7. Sacristán-Pérez-Minayo, G., López-Robles, D. J., Rad, C., Miranda-Barroso, L. (2020). Microbial Inoculation for Productivity Improvements and Potential Biological Control in Sugar Beet Crops. Frontiers in Plant Science, 11. doi: https://doi.org/10.3389/fpls.2020.604898

8. Aksu, G., Altay, H. (2020). The Effects of Potassium Applications on Drought Stress in Sugar Beet. Sugar Tech, 22 (6), 1092-1102. doi: https://doi.org/10.1007/s12355-020-00851-w

9. Magomedov, M. G. (2014). The technology of paste from sugar beet obtaining. Vestnik Voronezhskogo gosudarstvennogo universiteta inzhenernyh tekhnologiy, 3, 138-141.

10. Ursunbayeva, S. A., Iztayev, R., Gomedov, R., Yakiyayeva, A., Uldabekova, B. Z. (2019). Study of the quality of low-class wheat and bread obtained by the accelerated test method. Periódico Tchê Química, 16 (33), 809-822. doi: https://doi.org/10.52571/ptq.v16. n33.2019.824_periodico33_pgs_809_822.pdf

11. Iztayev, A., Kulazhanov, T. K., Yakiyayeva, M. A., Zhakatayeva, A. N., Baibatyrov, T. A. (2021). Method for the safe storage of sugar beets using an ion-ozone mixture. Acta Scientiarum Polonorum Technologia Alimentaria, 20 (1), 25-35. doi: https://doi.org/ 10.17306/j.afs.0865 